\title{
A rheological investigation of vesicular rhyolite
}

\author{
N.Sh. Bagdassarov and D.B. Dingwell \\ Bayerisches Geoinstitut, Universität Bayreuth, Postfach 101251, W-8580 Bayreuth, Germany
}

(Received June 10, 1991; revised and accepted September 18, 1991)

\begin{abstract}
Bagdassarov, N.Sh. and Dingwell, D.B., 1992. A rheological investigation of vesicular rhyolite. J. Volcanol. Geotherm. Res., 50: 307-322.

The rheology of vesiculating rhyolitic systems exerts a strong control on the transport of silicic magmas in the subvolcanic to volcanic environments. We present here an investigation of vesiculating and vesiculated rhyolites using dilatometric methods. This study examines the effect of vesicle content on the viscosity of a natural supercooled rhyolitic liquid with $0-70 \%$ vesicles.

The experimental samples of rhyolitic glass are derived from fusion of a natural obsidian from Little Glass Butte, Oregon. Crystal-free rhyolite glasses of varying porosity were prepared by fusing obsidian powder in a Pt crucible. Differing porosities were obtained by varying the temperature $\left(1300-1650^{\circ} \mathrm{C}\right)$ and duration $(0.5-6 \mathrm{~h})$ of the fusions. Cylindrical samples of the resulting vesiculated rhyolites were cored from the crucible using diamond tools and their ends were ground flat and parallel for dilatometry. The porosity of each sample was determined from Archimedean buoyancy density determinations and comparison with bubble-free rhyolite $\left(2.331 \mathrm{~g} / \mathrm{cm}^{3}\right.$, porosity $\left.=1-\rho / \rho_{\mathrm{o}}\right)$. The density of foamed samples was determined using their mass, volume and regular geometry.

Viscosities were determined in the parallel plate mode at stresses of $5 \times 10^{3}$ to $10^{5} \mathrm{~Pa}$. The viscosimeter was calibrated using NBS 711 glass. The bubble contents were microscopically investigated using a video-reflected light system and image analysis software. Distribution functions of the size, orientation, aspect ratio and surface porosity were obtained.

The viscosity of rhyolite decreases with increasing bubble content. A general relationship of the form: $\eta(f)=\eta(0) /$ $(1+C f)$, describes the effect of porosity, $f$ (in volume fraction) on the viscosity, $\eta$, where $C$ is a dimensionless constant $(=22.4 \pm 2.9)$ and $\log _{10} \eta(0)=10.94 \pm 0.04 \mathrm{~Pa}$ s at $850^{\circ} \mathrm{C}$.
\end{abstract}

\section{Introduction}

Recent progress in the physics and chemistry of magmatic processes leads to the conclusion that volatile exsolution and expansion of magmatic melts at shallow depths in the lithosphere is a major driving force of pyroclastic eruptions and pyroclast formation (c.f. Wilson et al., 1987). Recent investigation of the viscoelasticity of silicate melts indicates that non-Newtonian melt viscosity may precede such pyroclast formation (Dingwell and Webb,

Correspondence to: N. Bagdassarov, Bayerisches Geoinstitut, Universität Bayreuth, Postfach 101251, W-8580, Bayreuth, Germany.
1989; Webb and Dingwell, 1990). The nature of explosive eruptions can be explained in terms of critical fractional volume of exsolved bubbles (more than $70-80$ vol.\%) that leads to the disruption of foamed material, abrupt gas release and pyroclast formation (Sparks, 1978; Wilson et al., 1987). Explosive volcanic eruptions are, via these processes, responsible for plinian air-fall deposits and ignimbrites (Wilson et al., 1980). As emphasized by Sparks (1978), when a magma becomes supersaturated in volatiles by superheating or decompression, gas exsolves into spontaneously nucleated bubbles and the magmatic liquid becomes a disperse system. The rheological properties of a disperse magmatic system are 
not well known and this study is one of the first steps in that direction. Previous studies have concerned the cases of crystal + melt suspensions (Ryerson et al., 1988) and of dilute emulsions of melt + bubbles (Stein and Spera, 1992). The application of experimental results obtained on simple suspensions, such as Newtonian liquid+non-deformable spheres to magma flows may, however, ignore non-Newtonian effects specific to highly viscous dilatant fluids at low strain rates. As stressed by Wilson et al. (1987) volcanologists need, in general, a model of the rheology of disperse system in terms of size, shape, rigidity, and number-density distributions of the inclusions. This rheological model of magma should include non-Newtonian effects from different potential sources, such as the presence of deformable inclusions, volume viscosity, normal stress differences and relaxation processes.

The most abundant type of explosively erupted, high-viscosity, crystal-poor magma is rhyolite and this study concerns its rheological properties. There are many aspects to the vesiculation or separation of a gas phase from magmatic liquid. The kinetics of bubble nucleation and growth and the rate of separation have been studied experimentally (Murase and McBirney, 1973) and theoretically (Sparks, 1978). It has also been shown experimentally (Sakuyama and Kushiro, 1979) that transport

\section{Notations}

\footnotetext{
$\eta_{\mathrm{s}} \quad$ shear viscosity of suspension

$\tilde{\eta}_{\mathrm{s}} \quad$ shear viscosity of liquid

$\eta_{\mathrm{s}}^{0} \quad$ shear viscosity of inclusions

$\eta_{v} \quad$ volume viscosity of suspension

$\tilde{\eta}_{\mathrm{v}} \quad$ volume viscosity of liquid

$\eta_{\mathrm{v}}^{0} \quad$ volume viscosity of inclusions

$\eta_{1} \quad$ longitudinal viscosity

$\eta_{\mathrm{c}}$ compressional viscosity

$f$ volume fraction of inclusions

$K$ bulk modulus

$\mu \quad$ shear modulus
}

of alkali components in vapor phase during vesiculation at high pressure may play an important role in generating compositional variations in magma chambers. This is probably less important for shallow felsic magma chambers. Further, the size distribution of bubbles, relative to the conduit dimensions, can change the type or style of eruption (Vergniolle and Jaupart, 1986) and, depending on the level at which the disruption of foamed materials takes place, different forms of volcanic conduit can be produced (Wilson et al., 1980). Changes in water/magma mixing ratio and in the separation rate of pyroclasts and vapor from vertical flow in the magma column are reflected in variation of eruptive characteristics with time (Sheridan and Wohletz, 1981). Morphology and bubble-size distribution functions determined in vesiculated clasts (Toramaru, 1990) put constraints on the nucleation mode, the initial saturation pressure and the mean ascent velocity of magma. Finally, one may expect, in general, a strain-rate- (non-Newtonian) and time-dependent rheology for two-phase systems due to microstructural rearrangements or shear-induced diffusion across stream lines (Powell, 1988).

\section{Theoretical background}

Rheological characteristics of heterogeneous systems such as dilute emulsions or foams have been investigated experimentally and theoretically for several years (e.g., Schowalter, 1978; Kraynik, 1988). For a dilute emulsion which can be represented by a Newtonian liquid + spherical inclusions $(<10$ vol.\%) the main results may summarized as follows:

(1) The viscosity of a dilute suspension $\left(\eta_{\mathrm{s}}\right)$ of non-deformable gas bubbles gas the properties of a Newtonian liquid, with viscosity depending on the volume fraction of bubbles:

$\eta_{\mathrm{s}}=\tilde{\eta}_{\mathrm{s}}(1+f)$

(Taylor, 1932) where $\tilde{\eta}_{\mathrm{s}}$ is the shear viscosity 
of the liquid and $f$ is the volume fraction of bubbles.

(2) The presence of slightly deformed bubbles in Newtonian liquids results in non-linear effects, such as characteristic relaxation times and normal stress differences (Schowalter, 1978). If an incompressible fluid contains bubbles, the suspension has a volume viscosity:

$\eta_{\mathrm{v}}=4 \tilde{\eta}_{\mathrm{s}} / 3 f$

\section{(Taylor, 1954).}

(3) The relaxation time of suspension due to bubble deformation is proportional to $\sim R$ $\tilde{\eta}_{\mathrm{s}} / \sigma$ (Frankel and Acrivos, 1970). The form of bubbles participating in a slow viscous flow can be asymmetrical (Buckmaster, 1972) and under the influence of straining motion the bubbles flatten in the plane perpendicular to the flow, thus providing a resistance to collapse. The result is a dependence of compressibility on the porosity of glasses that has been observed experimentally (e.g. Walsh et al., 1965).

Shape changes of deformable drops in a suspension depend on two dimensionless parameters, the capillary number $C a$ and the viscosity ratio between the liquid and the drops $\lambda$ (Schowalter, 1978). The capillary number, $C a\left(=\dot{\epsilon} \tilde{\eta}_{\mathrm{s}} R / \sigma\right)$ describes the shear deformation of a bubble with respect to the interfacial tension seeking to maintain a spherical shape (where $\dot{\epsilon}$ is the strain rate, $R$ is the equivalent radius of the drop and $\sigma$ is the interfacial tension). In the case of gas bubbles suspended in a viscous melt $\lambda \Rightarrow 0$ and the capillary number is a measure of the deviation of bubble geometry from spherical. The case of small values of the capillary number $(C a<1)$ for melt + bubbles suspension has been experimentally investigated by Stein and Spera (1992). In the present study $C a>1$ with $\tilde{\eta}_{\mathrm{s}} \sim 10^{10}-10^{11} \mathrm{~Pa}$ s and $\dot{\epsilon} \sim 10^{-7}-10^{-5} \mathrm{~s}^{-1}$.

The main results on rheological studies of foams have been recently reviewed by Kraynik (1988) and may be summarized as follows:

(1) Diffusion processes in bubbles and a natural tendency of foams to diminish the surface area favor bubble growth. This causes foam instability under shear flow at high strain rates.

(2) At low strain rate there is excellent analogy between foams and highly concentrated liquid-liquid suspensions.

(3) Foams with a high volume fraction of bubbles $(>75 \%)$ are viscoplastic bodies with yield strengths which are strongly dependent upon the liquid fraction. (There are other nonNewtonian features of foam rheology like "slip on the wall" and changing of geometry under shear flow which are not relevant to the present study.)

The dependence of viscosity on porosity or bubble content in glasses and highly viscous liquids $\left(\tilde{\eta}_{\mathrm{s}}>10^{9} \mathrm{~Pa} \mathrm{~s}\right)$ differs from relationship (1) and others (cf. Stein and Spera, 1992) obtained for liquid + bubble suspensions. Theoretical analysis and experimental testing of different relationships between the viscosity and porosity of glasses (Sura and Panda, 1990) illustrate the decrease of glass viscosity with porosity increase. McKenzie's (1950) analysis of dilute pores results in a viscosity dependence $\left(\eta_{\mathrm{s}}\right)$ vs. porosity $(f)$ of:

$\eta_{\mathrm{s}}=\tilde{\eta}_{\mathrm{s}}(1-\alpha f)$

which is valid at low porosity $(f \ll 1)$. A more complicated expression (Sura and Panda, 1990 ) derived by using the viscous analogy of elastic stresses and including a shape factor for pores $(\Omega)$ is:

$\eta_{\mathrm{s}}=\tilde{\eta}_{\mathrm{s}} \frac{3 \Omega(1-f)^{2}}{3 \Omega(1-f)+2 f}$

(For spherical pores, $\Omega=1$, and $\Omega \Rightarrow 0$ when pores completely enclose the solid particles.) In the case of spherical non-interacting inclusions at low porosities the dependence of viscosity on volume fraction of bubbles should be linear as in eqn. 3 whereas at high porosities $(f>0.5)$, as demonstrated experimentally, $\eta_{\mathrm{s}} \sim 1 / f$ (Sura and Panda, 1990). In order to reconcile these two conditions it is reasonable 
to fit the experimental data of viscosity versus porosity to a relationship such as:

$\eta_{\mathrm{s}}(f)=\frac{\tilde{\eta}_{\mathrm{s}}(0)}{1+C f}$

which yields the linear approximation (3) at low porosity $(f \Rightarrow 0)$.

\section{Experimental method}

\section{Sample preparation}

Obsidian from Little Glass Butte, Oregon was chosen for this investigation. The composition of rhyolite obtained from melting of the obsidian has been determined previously (Webb and Dingwell, 1990) and is reproduced in Table 1. The initial water content of the obsidian was determined by Karl Fischer titration to be $\mathrm{H}_{2} \mathrm{O}^{+}=0.17 \pm 0.02$ wt. \%, $\mathrm{H}_{2} \mathrm{O}^{-} \approx 0.03$ wt.\%. In order to produce samples with different bubble contents a special procedure of powder sintering was developed. Temperature, grain size and sintering duration were varied to obtain different specimens of rhyolite glass with bubbles. A cobble of obsidian was ground into a $100-400 \mu \mathrm{m}$ powder using a steel mortar, agate mortar and sieves. Powders of obsidian were melted in a $50-\mathrm{cm}^{3}$ thin-walled $\mathrm{Pt}_{95} \mathrm{Au}_{5}$ crucible in a $\mathrm{MoSi}_{2}$ element box furnace. To produce low porosities

TABLE 1

Composition of rhyolite samples (wt.\%)

\begin{tabular}{lccc}
\hline Oxide & Starting material & Porous glass & Foamed sample \\
\hline $\mathrm{SiO}_{2}$ & 77.7 & 78.6 & 78.6 \\
$\mathrm{TiO}_{2}$ & 0.06 & 0.09 & 0.07 \\
$\mathrm{Al}_{2} \mathrm{O}_{3}$ & 13.0 & 12.8 & 12.7 \\
$\mathrm{FeO}$ & 0.71 & 0.62 & 0.85 \\
$\mathrm{MnO}$ & 0.03 & 0.02 & 0.03 \\
$\mathrm{MgO}$ & 0.05 & 0.06 & 0.05 \\
$\mathrm{CaO}$ & 0.53 & 0.59 & 0.56 \\
$\mathrm{Na}_{2} \mathrm{O}$ & 4.06 & 3.02 & 3.00 \\
$\mathrm{~K}_{2} \mathrm{O}$ & 4.18 & 4.15 & 4.10 \\
\hline
\end{tabular}

Camebax microprobe is $15 \mathrm{kV}, 10 \mathrm{nA}$ on brass, $15 \mathrm{~s}$ count times.
1:1 mixes of obsidian and pre-melted rhyolite glass were used as the starting materials for sintering. Powders were mixed by agitation. Prepared samples of porous and foamed rhyolite glass were removed from the furnace and placed into a second furnace. There they were heated to $1150^{\circ} \mathrm{C}$, held at that temperature for 1 hour and cooled slowly over 12 hour by switching off power to the furnace. This procedure avoids cracks due to thermal stresses during cooling. In Table 2 there is a list of specimens with different thermal histories and porosities $(f)$.

Cylindrical samples of vesicular rhyolite ( 8 $\mathrm{mm}$ in diameter and $5-20 \mathrm{~mm}$ in length) were cored from the crucible using diamond tools and the ends of the cylinders were ground flat and parallel. The density of each sample was determined from Archimedean buoyancy determinations (in toluol and air) at $22^{\circ} \mathrm{C}$ and then compared with bubble-free rhyolite $\left(\rho_{0}=2.331 \mathrm{~g} / \mathrm{cm}^{3}\right)$ using a laboratory balance Mettler AE 160 having a precision $1 \times 10^{-4} \mathrm{~g}$. The porosity was then determined as $(1-\rho)$ $\left.\rho_{0}\right)$. The standard error of the density measurements is $\pm 0.003 \mathrm{~g} / \mathrm{cm}^{3}$. The Archimedean buoyancy measurements of foamed sample densities lead to rather high errors because of the toluol saturation of the pores that breach the sample surface. A second method therefore was used for porosity determination of foamed samples. This consisted of measuring the mass and volume of the regular cylindrical shape. The standard error of this method is $\pm 0.01 \mathrm{~g}$ / $\mathrm{cm}^{3}$.

The samples so obtained can be divided into two groups: (1) porous glasses with a porosity of less than $4-5 \%$ and (2) foamed samples with a porosity of $25-67 \%$. Intermediate porosity was found to be difficult to produce because of nonuniform collapse of bubbles near the surface of the melt and Ostwald ripening process. Room temperature densities were corrected for $850^{\circ} \mathrm{C}$ taking into account thermal expansion of the rhyolite glass $\left(6 \times 10^{-6} \mathrm{~K}^{-1}\right)$ and foamed materials $\left(2 \times 10^{-5} \mathrm{~K}^{-1}\right)$. These ex- 
TABLE 2

Description of specimens

\begin{tabular}{|c|c|c|c|c|c|c|}
\hline No. sample & Sintering procedure & $\begin{array}{l}\text { Density } \\
\left(\mathrm{g} / \mathrm{cm}^{3}\right)\end{array}$ & $\begin{array}{l}\text { Porosity } \\
(\%)\end{array}$ & $\begin{array}{l}\text { Surface } \\
\text { porosity }(\%)\end{array}$ & $\begin{array}{l}\text { Mean size } \\
(\mu \mathrm{m})\end{array}$ & $\begin{array}{l}\text { Max size } \\
(\mu \mathrm{m})\end{array}$ \\
\hline 63 & Fused powder of rhyolite glass at $T=1650^{\circ} \mathrm{C}$ for $6 \mathrm{~h}$ & 2.295 & 1.5 & 4.8 & 60 & 120 \\
\hline 64 & $\begin{array}{l}\text { Mixture of fused glass powder and powder of } \\
\text { obsidian }(1: 1) \text { at } T=1360^{\circ} \mathrm{C} \text { for } 2 \mathrm{~h}\end{array}$ & 2.260 & 3.1 & 6.9 & 100 & 170 \\
\hline 65 & $\begin{array}{l}\text { Mixture of fused powder of rhyolite glass and } \\
\text { powder of obsidian }(1: 1) \text { at } T=1380^{\circ} \mathrm{C} \text { for } 4 \mathrm{~h}\end{array}$ & 2.225 & 4.5 & 11.5 & 90 & 220 \\
\hline 66 & $\begin{array}{l}\text { Mixture of fused powder of rhyolite glass and } \\
\text { powder of obsidian }(1: 1) \text { at } T=1370^{\circ} \mathrm{C} \text { for } 2 \mathrm{~h}\end{array}$ & 2.245 & 3.7 & 5.1 & 70 & 150 \\
\hline 68 & $\begin{array}{l}\text { Mixture of fused powder of rhyolite glass and } \\
\text { powder of obsidian }(1: 1) \text { at } T=1340^{\circ} \mathrm{C} \text { for } 2 \mathrm{~h}\end{array}$ & 2.275 & 2.4 & 5.3 & 100 & 220 \\
\hline 69 & Fused powder of obsidian at $T=1400^{\circ} \mathrm{C}$ for $2 \mathrm{~h}$ & 0.780 & 66.5 & 67.2 & 430 & 800 \\
\hline 70 & $\begin{array}{l}\text { Fused powder of rhyolite glass at } T=1300^{\circ} \mathrm{C} \text { for } \\
0.5 \mathrm{~h}\end{array}$ & 2.270 & 2.6 & 6.5 & 70 & 130 \\
\hline 71 & $\begin{array}{l}\text { Fused powder of obsidian glass at } T=1400^{\circ} \mathrm{C} \text { for } \\
0.5 \mathrm{~h}\end{array}$ & 1.550 & 33.5 & 41.6 & 200 & 400 \\
\hline 73 & $\begin{array}{l}\text { Mixture of fused powder of rhyolite glass and } \\
\text { powder of obsidian }(1: 1) \text { at } 1420^{\circ} \mathrm{C} \text { for } 0.5 \mathrm{~h}\end{array}$ & 0.750 & 67.8 & 73.4 & 350 & 600 \\
\hline 75 & $\begin{array}{l}\text { Mixture of fused powder of rhyolite glass and } \\
\text { powder of obsidian }(1: 1) \text { at } T=1380^{\circ} \mathrm{C} \text { for } 1 \mathrm{~h}\end{array}$ & 1.740 & 25.4 & 33 & 250 & 500 \\
\hline 76 & $\begin{array}{l}\text { Mixture of fused powder of rhyolite glass and } \\
\text { powder of obsidian }(1: 1) \text { at } T=1380^{\circ} \mathrm{C} \text { for } 1 \mathrm{~h}\end{array}$ & 2.255 & 3.3 & 8.2 & 90 & 200 \\
\hline
\end{tabular}

pansivities were measured in a dilatometer (described below). Because of water vapor exsolution from rhyolite melt during bubble formation there is a source of error in porosity estimation related to the non-zero density of gas inside the bubbles. At a temperature of $1200-1300^{\circ} \mathrm{C}$ and a pressure of $1 \mathrm{bar}$, density of water is not more than $10^{-3} \mathrm{~g} / \mathrm{cm}^{3}$, so the systematic error in porosity is $f^{*} \rho_{\mathrm{H}_{2} \mathrm{O}}$ $\left(1300^{\circ} \mathrm{C}\right) / \rho_{\text {rhyolite }}$ Thus, the maximum error in density measurements was $1 \%$ for foamed materials.

\section{Vesiculation rate measurements}

Rates of vesiculation were estimated using a cylindrical thick-walled $\mathrm{Pt}_{80} \mathrm{Rh}_{20}$ viscometry crucible (Dingwell and Virgo, 1988) by measuring the volume of vesicular rhyolite melt. This was done by filling the free space with distilled water and measuring the weight difference. Room temperature measurements of volume were corrected for $1400^{\circ} \mathrm{C}$ using the thermal expansion coefficient of rhyolite glass and foam. Table 3 shows the approximate rate of vesiculation at $1400^{\circ} \mathrm{C}$. When the foam grows the system of pores seems to be unconnected. After reaching of $\sim 75$ vol. $\%$ vesicles begin to coalesce and porosity decreases with time. Experiments on gas release in felsic glasses (Hampton and Bailey, 1984) have shown that bubble formation is controlled by viscosity. The emission of all gas species in obsidian has a peak at melting temperature range

TABLE 3

Vesiculation rate of rhyolite $\left(T=1400^{\circ} \mathrm{C}\right)$

\begin{tabular}{lll}
\hline $\begin{array}{l}\text { Time } \\
(\mathrm{h})\end{array}$ & $\begin{array}{l}\text { Density } \\
\left(\mathrm{g} / \mathrm{cm}^{3}\right)\end{array}$ & $\begin{array}{l}\text { Porosity } \\
(\%)\end{array}$ \\
\hline 0.3 & 1.275 & 45 \\
1.0 & 1.920 & 17.6 \\
1.2 & 2.045 & 12.3 \\
1.7 & 2.125 & 8.8 \\
2.0 & 2.230 & 4.3 \\
2.2 & 2.245 & 3.7 \\
3.0 & 2.265 & 2.8 \\
4.7 & 2.290 & 1.8 \\
6.0 & 2.320 & 0.5 \\
\hline
\end{tabular}


$900-1050^{\circ} \mathrm{C}$. Nevertheless it is practically impossible to get our obsidian to foam at this temperature range because of its high viscosity. At temperatures higher than $1500^{\circ} \mathrm{C}$ the lifetime of the foam is very short (Cooper and Kitchener, 1959). Also the lifetime of the foam decreases in the following order with different gas contents in bubbles (Kappel et al., 1987):

air $>\mathrm{CO}_{2} \approx \mathrm{N}_{2}>\mathrm{SO}_{2}$

Experiments with rhyolite show that the transition from foamed material (with volume fraction of bubbles $\sim 70 \%$ ) to liquid with bubbles (dilute emulsion with volume fraction of bubbles $\sim 5 \%$ ) happens during very short period of time $(<2000 \mathrm{~s})$. A gas-chromatograph analysis of bubble compositions from our samples obtained in a special "crushing cell" showed a significant amount of $\mathrm{SO}_{2}$ in bubble gas content of foams (B. Coté, Saint-Gobain Recherche, France, pers. commun., 1991). A further decrease of porosity develops in time very slowly even at temperatures higher than $1600^{\circ} \mathrm{C}$. To produce glass samples with vanishing porosity, in air, one needs for example to stir the meit at $1650^{\circ} \mathrm{C}$ for 8 days (Webb and Dingwell, 1990).

\section{Rheology measurements}

The obtained glass cylinders were studied in a parallel plate viscometer. The cylinder strain was measured using a commercial dilatometer (Model TMA 402 ${ }^{\circledR}$, Netzsch Geratebau, Selb, Germany). A schematic illustration of this device is shown on Figure 1 and an explanation of its construction is given by Webb and Dingwell (1990). For use as a parallel plate viscometer a silica glass rod is connected to a weight pan through the vanadium rod. The sample under investigation is placed between two polished alumina (AL23 ${ }^{\circledR}$, Friedrichsfeld) plates with diameter $\sim 10 \mathrm{~mm}$ and with silica glass rod contacting the upper plate. A compressive stress is applied to the sample by loading weights on the weight pan. The compression of

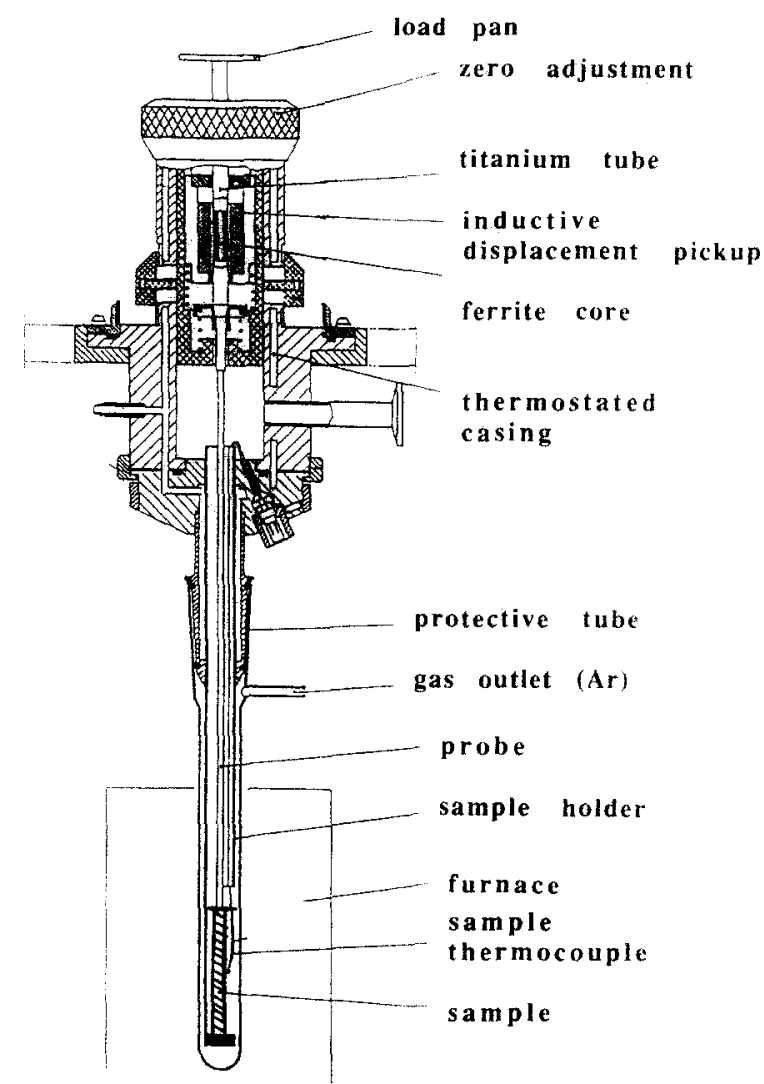

Fig. 1. Schematic illustration of the dilatometer used in parallel plate viscometry.

the specimen is monitored by the movement of the vanadium rod through the center of a calibrated linear voltage displacement transducer (LVDT).

The theory of parallel plate viscometry is described in the literature (e.g., Gent, 1960). The method of parallel plate viscometry has some advantages for measurements of high viscosity $\left(10^{7}-10^{11} \mathrm{~Pa} \mathrm{~s}\right)$ in comparison with fiber elongation (Fontana, 1970). The parallel plate geometry has been chosen to allow viscosity measurements in rhyolite samples with varying fraction of bubbles. For incompressible samples which effectively adhere to the plates one can use the equation for calculating viscosity:

$\eta_{\mathrm{s}}=\frac{2 \pi M g h^{5}}{3 V(\mathrm{~d} h / \mathrm{d} t)\left(2 \pi h^{3}+V\right)}$ 
which is valid for a wide range of radius-thickness combinations (Gent, 1960). $M$ is the applied load, $\eta_{\mathrm{s}}=$ viscosity, $g=$ gravitational acceleration, $V=$ specimen volume, $h=$ specimen height at time $t$. The load $M$ applied to the sample is calculated from the half weight of the sample plus the weight of all parts attached to the movable parallel plate (approx. $1 \mathrm{~g}$ ) plus the additional weight put on the load pan. Expression (7) may be applied only to incompressible samples. In case of compressible high porosity materials the modified expression for slip boundary conditions (Gent, 1960):

$$
\eta_{\mathrm{s}}=\frac{M g h}{3(\mathrm{~d} h / \mathrm{d} t) S_{\mathrm{eff}}}
$$

is used because the diameter of foamed samples was unchanged after the experimental runs. Room temperature measurements of effective surface area $\left(S_{\text {eff }}\right)$ were corrected for thermal expansion using the aforementioned thermal expansion coefficients.

Because of porosity the effective surface to which the load applied is less than that given by the external cylinder geometry. To take this into account the effective surface area of contact was calculated using a surface porosity term $\left(f_{\text {surf }}\right)$ :

$S_{\text {eff }}=S^{*}\left(1-f_{\text {surf }}\right)$

This was determined from the cross-sectional image analysis of samples. The geometry of each specimen was measured with a micrometer with an accuracy of $0.01 \mathrm{~mm}$ and volume was calculated using their regular geometry. Height, $h(t)$ at the time $(t)$ of measurements was determined from initial thickness of sample plus thermal expansion during heating and minus the recorded displacement of the quartz rod during the experiment. The parallel plate viscosimeter was calibrated using samples of NBS 711 with the same geometry and at a similar viscosity (i.e. temperature of $487^{\circ} \mathrm{C}$ ). Calibration with NBS 711 , using a loading and unloading procedure, showed significant systematic error deriving from an ef- fective stress not equal to that calculated from the applied weight. This difference is due to some friction in mechanical system. NBS 711 glass viscosity was used as a working standard to calculate the effective stress on the sample. All measurements of rhyolite samples were corrected using the NBS 711 data by introducing the multiplicative factor for each applied stress.

Stresses which were applied to samples in experiments varied from $5 \times 10^{3}$ to $1 \times 10^{5} \mathrm{~Pa}$. A loading and unloading procedure was used both for calibration and for viscosity measurements in rhyolite samples. A typical relationship between strain rate and applied stress is shown on Figure 2 for porous rhyolite (a) and foamed rhyolite (b). (Note that the stresses indicated in Figure 2, are the uncorrected stresses applied to the sample. Effective stresses used in calculation of rhyolite sample viscosity were then subsequently corrected for systematic error.) After the application of each additional mass the compression of the cylinder was monitored at $12-\mathrm{s}$ intervals for $30 \mathrm{~min}$. The first $10 \mathrm{~min}$ were excluded from calculations because of a time dependence of the compressional strain rate and to ensure the absence of unrelaxed melt deformation (viscoelasticity). Measured strain rate varies in the range of $10^{-7}-10^{-6} \mathrm{~s}^{-1}$ for porous rhyolites and in the range of $10^{-6}-10^{-5} \mathrm{~s}^{-1}$ for foamed rhyolites. Over studied interval of strain rate the apparent measured viscosity is independent of the deformation rate. The stress-strain rate data show some hysteresis in Figure 2 . The calibration experiments with NBS711 showed that the hysteresis is to be attributed to the mechanical system of the viscometer at small loads rather than to non-Newtonian behavior of the samples. The standard error of viscosity determinations is $0.08-0.14 \log _{10}(\mathrm{~Pa} \mathrm{~s})$. The cumulative deformation of samples was checked after each experiment. These cumulative deformations of the samples never exceeded 1$1.5 \%$. For samples with low porosity $(<4.5 \%)$ the volume after the experiment was un- 

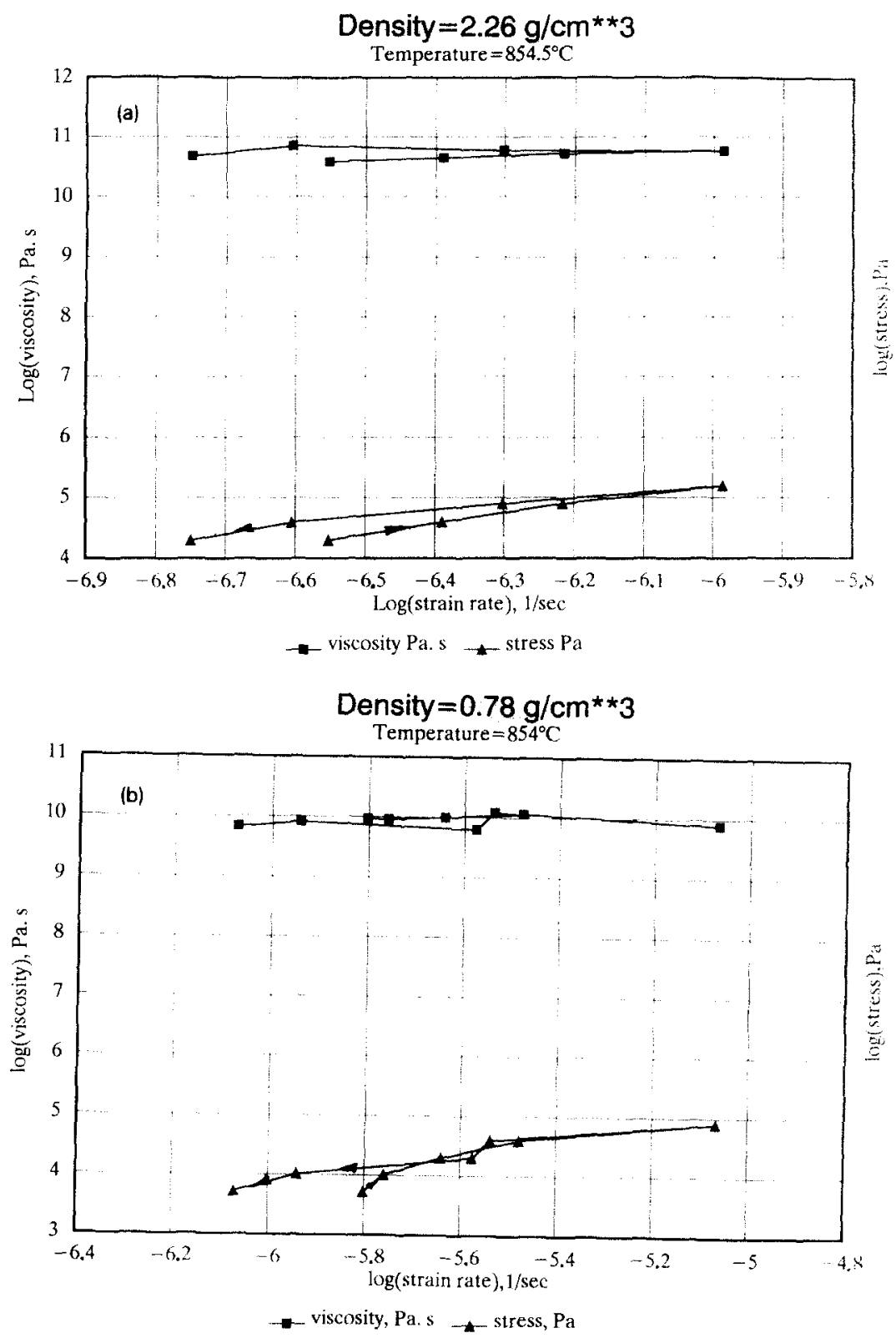

Fig. 2. Results of dilatometric measurements of compressional viscosity for porous (a) and foamed (b) samples.

changed. For foamed materials with a porosity of $65-67 \%$ the volume decreases proportionally to the height. All measurements were carried out in the temperature range $847-854^{\circ} \mathrm{C}$ just above the glass transition of rhyolite and thus the samples are highly viscous liquid suspensions. The viscosities in Figure 2 are apparent compressional viscosities. At low porosi- ties the value of apparent compressional viscosity is close to the results of fiber elongation experiments (Webb and Dingwell, 1990) on the same rhyolite without bubbles. At high porosity ( $>20 \mathrm{vol} . \%$ ) the effective viscosity is practically constant and equal to $\sim 10^{10} \mathrm{~Pa} \mathrm{~s}$. A general relationship between porosity and effective compressional viscosity can be ex- 


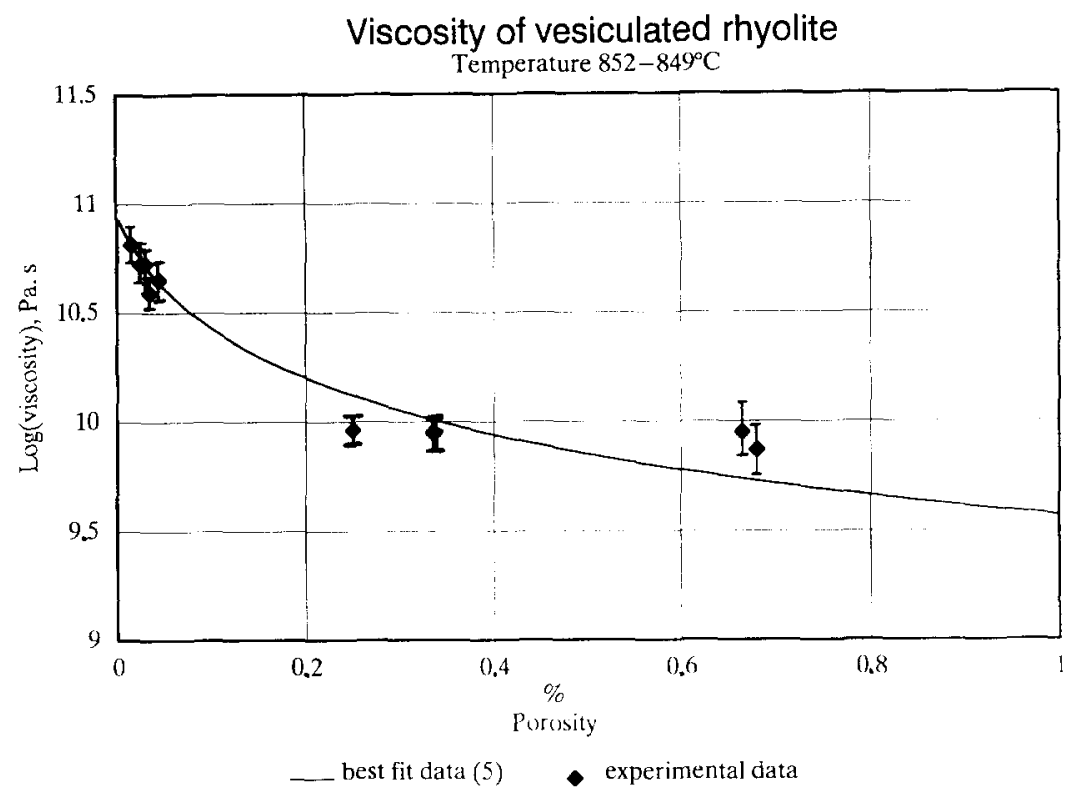

Fig. 3. Viscosity of rhyolite samples as a function of porosity.

pressed in the form (5) where $\log _{10}$ $\eta_{\mathrm{s}}(0)=10.94 \pm 0.04 \mathrm{~Pa} \mathrm{~s}, f$ is porosity and $C$ is a dimensionless constant $=22.4 \pm 2.9$. A master curve of compressional viscosity measurements is shown in Figure 3.

\section{Bubble distribution}

After experiments samples were sectioned and cross sections were studied using a reflected light microscope. The images were analyzed on Tracor Northern TN-8500 ${ }^{\circledR}$ Image Analysis System. The grey image from videocamera was processed into a binary image in order to perform statistical analysis. For every specimen the distribution functions of average size, shape factor, orientation angle of bubbles were obtained. The size of bubbles is estimated as the mean value of all distances considered in the determination of the maximum and minimum projections. The shape factor is taken as the ratio of the maximum projection to the width the bubble projection perpendicular to the maximum projection. Orientation is calculated as the direction of the maximum projection in degrees.
Surface porosities were compared with the results of density measurements (Table 2 ). The cross sections were analyzed at different points: center middle, center edge, top and middle, bottom and top edge.

The measured average spherical particle size from planar image differs from spatial statistics. The usual way to describe the spatial density distribution function $f(R)$ of particle sizes from $g(R)$ (planar density distribution function of particle sizes ) of their observed sizes in a planar section is by use of an empirical histogram (e.g., Cashman, 1990). If $a_{i}, b_{i}, w_{i}$ are midpoints, upper limits and width of size bins then one has to solve the system of equations (Ripley, 1981):

$w_{i} g\left(a_{i}\right)=a_{i} \sum_{j \geq i} w_{j} f\left(a_{j}\right) /\left[m\left(b_{j}^{2}-a_{i}^{2}\right)^{1 / 2}\right]$

where $g\left(a_{i}\right)$ are known and $f\left(a_{j}\right)$ are unknown. Here, $m$ is the first moment of spatial distribution function and can be estimated as $m \approx \pi /\left(2 \sum 1 / r_{i}\right)$ where $r_{i}$ are measured planar diameters. The system of linear equations can be resolved by iterative procedure and spatial size distribution function $f\left(a_{i}\right)$ may be ob- 

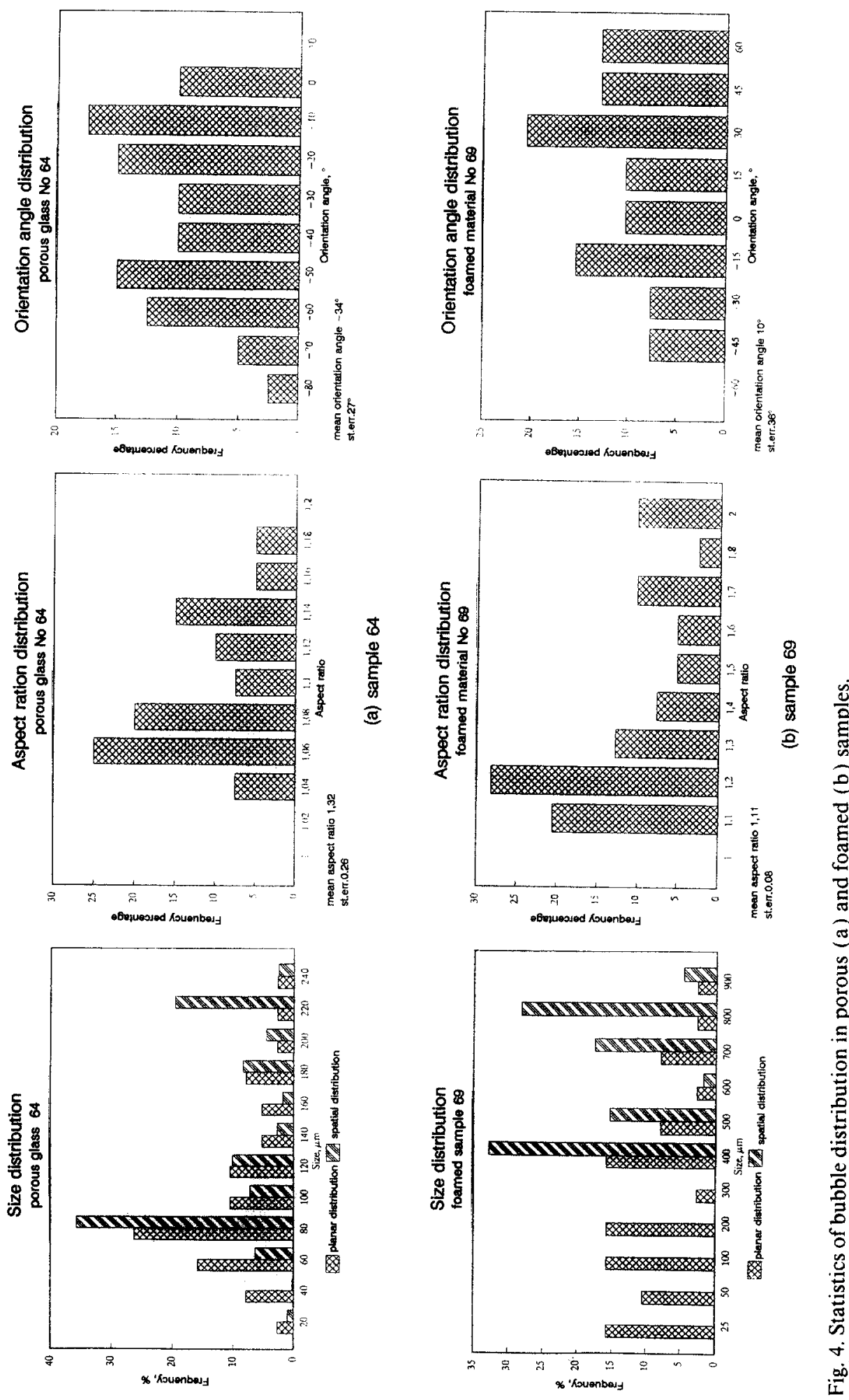
tained. If $f\left(a_{i}\right)$ for some small bin is negative the density for this bin and all smaller diameters are set to zero (Ripley, 1981). This procedure was applied to results of image analysis.

The porous glasses contain smaller bubbles with 80 and $220 \mu \mathrm{m}$ of average and maximum diameters of cross section, respectively (Fig. $4 a)$. The planar size distribution function is close to a Gaussian distribution. The foamed materials are characterized by large bubbles with average and maximum cross-section diameters 300 and $800 \mu \mathrm{m}$, respectively (Fig. $4 b)$. Planar size distribution function deviates from Gaussian due to Ostwald ripening processes. In foamed materials bubbles are deformed and have an aspect ratio 1.15-1.30 and orientation perpendicular to the applied stress. In porous glasses the bubbles have aspect ratio close to 1 . They are practically undeformed and have mean preferred orientation of $-45^{\circ}$ for the left upper quadrant (Fig. 4a). It should be noticed that the orientation angle data are scattered and the precision of bubble orientations having the aspect ratio close to 1 is low. Nevertheless, qualitatively, the preferable orientation of bubbles is perpendicular to the stream line of viscous flowing. In some cases it was noticed that, on the contact with the free surface of the sample small bubbles (less $50 \mu \mathrm{m}$ in diameter) behave as hard spheres. The planar coordination number for the biggest bubbles in foamed materials is 7-8.

Within the accuracy of the experiments it can be stated that in foamed materials deformation of specimen is controlled by viscous deformation of big bubbles uniform throughout the sample. Preferable elongation of bubbles is perpendicular to the stream line of material flowing under applied stresses.

\section{Discussion}

The materials which have been studied here may be described as porous glasses (dilute suspensions) with volume fraction of bubbles $<5 \%$ and foamed samples with volume frac- tion of bubbles $25 \%<f<70 \%$. Their viscosity has been measured at temperatures near the glass transition $\left(\sim 850^{\circ}\right)$ and at low strain rate $\left(10^{-7}-10^{-5} \mathrm{~s}^{-1}\right)$ using parallel plate viscometer. At this range of viscosity $\left(10^{10}-10^{11} \mathrm{~Pa}\right.$ s) it is possible to use the viscous analogy to derive their viscosity dependence on porosity from elastic stress analysis (cf. Sura and Panda, 1990). If the sample is incompressible under uniaxial compression or elongation one measures instead of shear viscosity $\left(\eta_{\mathrm{s}}\right)$ longitudinal viscosity $\left(\eta_{1}\right)$, which appears as the analog of Youngs modulus in the elastic case:

$$
\frac{9 K \mu}{3 K+\mu}
$$

If the deformation is pure compression one measures compressional viscosity $\left(\eta_{\mathrm{c}}\right)$ which the elastic analog is:

$K+4 / 3 \mu$

where $K$ is the bulk modulus and $\mu$ is shear modulus.

The present experimental data indicate that the apparent compressional viscosity measured in vesicular samples decreases in 1 order of magnitude with porosity increase up to $25 \%$ and then remains constant. The question remains as to what type of viscosity is recorded in these experiments and how it relates to shear and volume viscosity of the material. At low porosity the deformation character of samples indicates practically incompressible behavior. This means that the measured viscosity is longitudinal $\left(\eta_{1}\right)$ and relates to shear $\left(\eta_{\mathrm{s}}\right)$ and volume viscosity of material $\left(\eta_{\mathrm{v}}\right)$ as (cf. Sura and Panda, 1990):

$\eta_{1}=\frac{9 \eta_{\mathrm{s}} \eta_{\mathrm{v}}}{3 \eta_{\mathrm{v}}+\eta_{\mathrm{s}}}$

At high porosity, the character of sample deformation indicates pure uniaxial compression and in this case the measured viscosity is:

$\eta_{\mathrm{c}}=\eta_{\mathrm{v}}+4 / 3 \eta_{\mathrm{s}}$

The dependence of shear and volume vis- 
cosity of the medium on porosity can be given by the viscous analogy of the elastic bulk modulus and shear modulus, $K$ and $\mu$ to the volume and shear viscosities, $\eta_{\mathrm{v}}$ and $\eta_{\mathrm{s}}$, respectively (cf. Sura and Panda, 1990). The theoretical dependence of the elastic modulus on porosity may be obtained by the self-consistent approach well described in the literature (Watt et al., 1976). If one sets volume ( $\left.\eta_{\mathrm{v}}^{0}\right)$ and shear $\left(\eta_{\mathrm{s}}^{0}\right)$ viscosity of the material in the spherical inclusions to zero then at $50 \%$ of porosity $\eta_{1}$ and $\eta_{\mathrm{c}}$ tends to zero. If $\eta_{\mathrm{v}}^{0}$ is slightly differs from 0 then at $50 \%$ of porosity $\eta_{c}$ tends be constant and equal to volume viscosity of porous medium. Figure 6 shows these two different cases where results of calculations of $\eta_{1}$ (a) and $\eta_{c}$ (b) are presented. The comparison of these relationships with experimental results give the
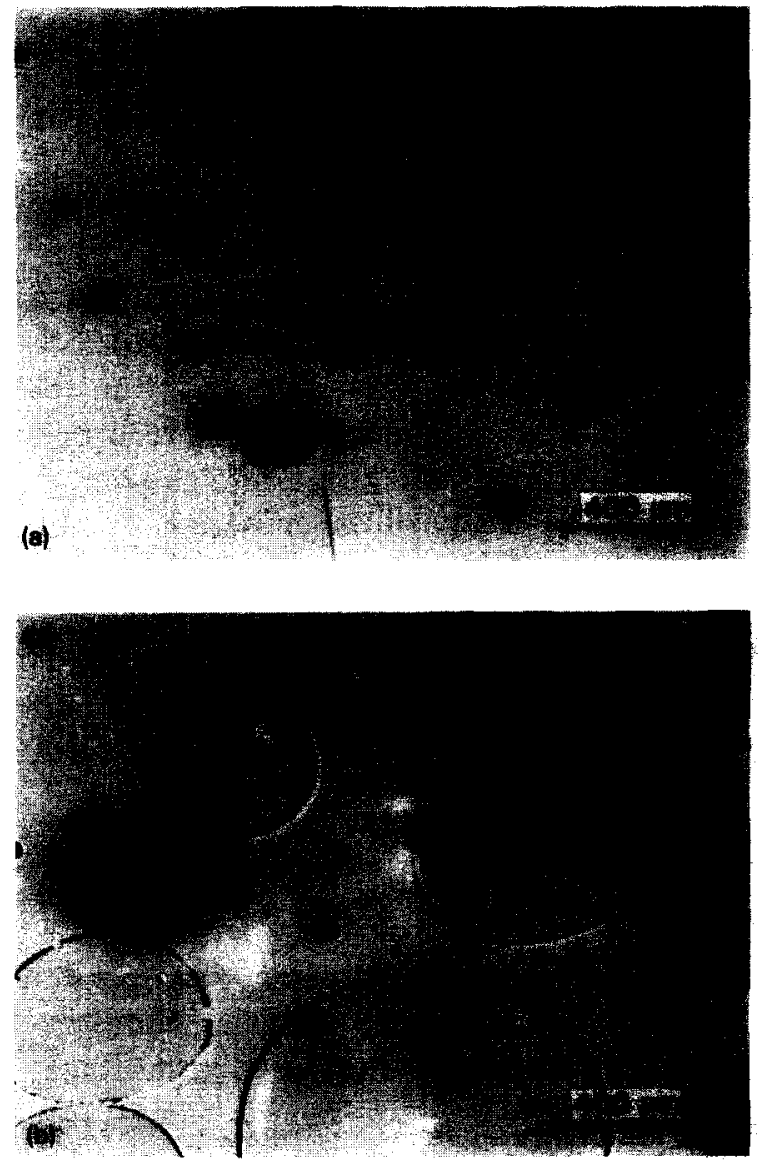

Fig. 5. Photos of sample cross section.
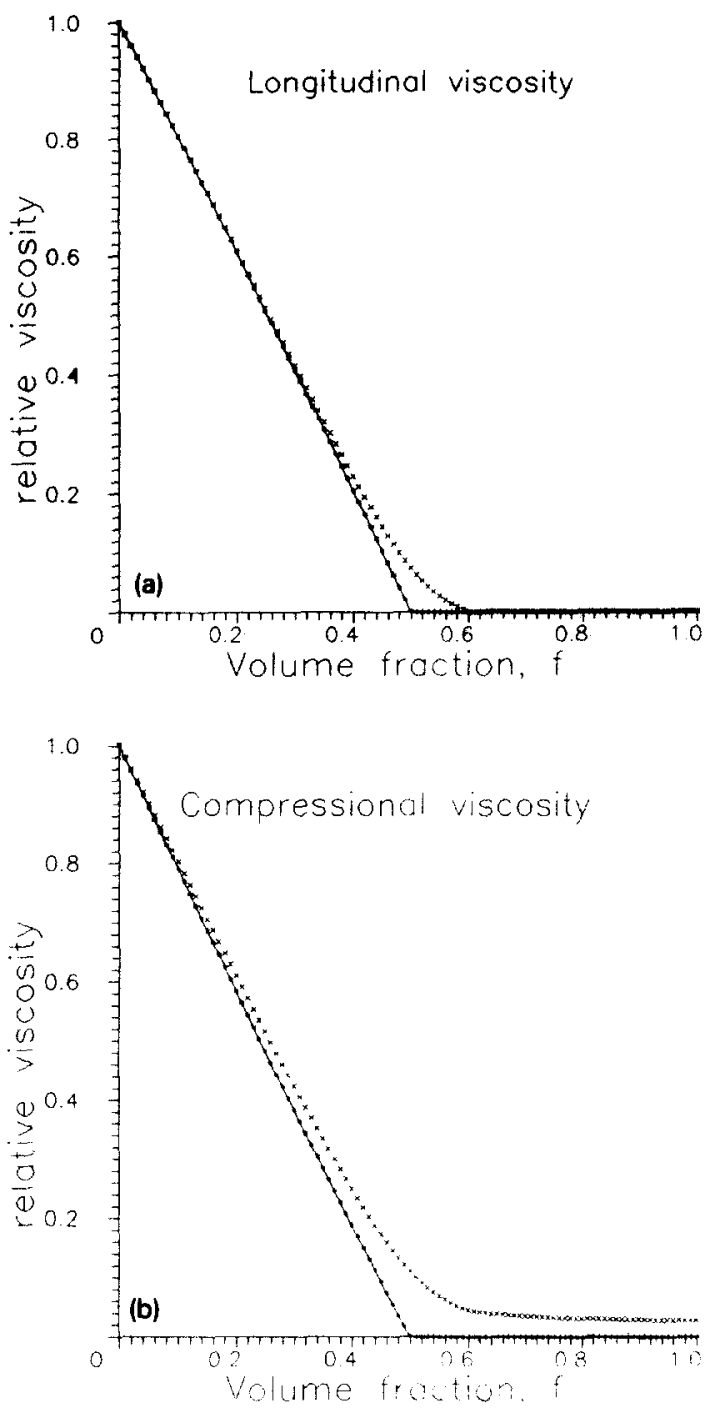

$\ldots$ volume viscosity of inciustom

${ } x_{x}$. volume viscosity of inclusions/glas

Fig. 6. Calculated longitudinal (a) and uniaxial compressional (b) viscosities of a spherical inclusion suspension according to the self-consistent approach (see Appendix).

following explanation of measured viscosity vs. porosity. At low porosity apparent measured viscosity is $\eta_{1}$ and linearly decreases with volume fraction of bubbles. At high porosity the apparent measured viscosity is $\eta_{\mathrm{c}}$ and this becomes constant.

Alternatively, the measured values of viscosity of Figure 3 can be explained in the following manner. According to the self-consis- 
tent approach, when $f \ll 1$, the volume viscosity relates to the shear viscosity of a porous body as:

$\eta_{\mathrm{v}}=4 / 3 \eta_{\mathrm{s}}(1-f) / f$

Using eqn. 12 and the relationship between $\eta_{\mathrm{s}}$ and $\tilde{\eta}_{\mathrm{s}}$ :

$\eta_{\mathrm{s}}=\tilde{\eta}_{\mathrm{s}}\left(1-\frac{5}{3} f\right)$

which comes from the viscous analogy of shear modulus in a porous medium (McKenzie, 1950 ) one obtains the dependence of apparent viscosity measured at low porosity and volume fraction of voids in form:

$\eta_{1} / \tilde{\eta}_{\mathrm{s}}=\frac{(1-f)}{(1-0.75 f)}\left(1-\frac{5}{3} f\right)$

When $0 \ll f<1$ instead of eqn. 14 a second expression is preferred:

$\eta_{\mathrm{v}}=4 / 3 \eta_{\mathrm{s}}\left(1-f+0.5 f^{2}\right) / f$

(Skorokhod, 1972) which is applicable at high porosities $(f>0.66)$. Instead of eqn. 15 at high porosities one uses:

$\eta_{\mathrm{s}}=\tilde{\eta}_{\mathrm{s}}(1-f)^{5 / 3}$

Finally, at high porosities, the apparent viscosity vs. volume fraction of bubbles can be expressed in the form:

$\eta_{\mathrm{c}} / \tilde{\eta}_{\mathrm{s}}=4 / 9(1-f)^{5 / 3}\left(1 / f+0.5 f^{2}\right)$

In Figure 7 normalized data of apparent measured relative viscosity $\eta_{\mathrm{l}, \mathrm{c}} / \tilde{\eta}_{\mathrm{s}}$ are shown in comparison with calculated date according to eqns. 16 and 19. The noticeable discrepancy at high porosity can be explained by the neglecting volume viscosity of vapor in bubbles at $850^{\circ} \mathrm{C}$. At low porosity the standard error in normalized viscosity determination dominates and precludes further discussion.

The new experimental result obtained in this study leads to some new interpretations of obsidian flow phenomena. Previous views on the dependence of the viscosity of rhyolitic obsidian on vesicularity have not taken into ac- count the decrease of viscosity with increase in bubble volume during compression or elongation flow. For example, in discussions about the nature of extrusive rhyolites (Friedman, 1989; Eichelberger, 1989) one of the arguments in favor the hypothesis that "dry" obsidians (0.10.3 wt. $\% \mathrm{H}_{2} \mathrm{O}$ ) remained "dry" at the depth was the absence of vesiculation in obsidians on the surface. Measurements of vesiculation rate show, however, that to obtain rhyolite glass without bubbles at temperatures lower than $1250^{\circ} \mathrm{C}$ is practically impossible. If extrusive rhyolites resulted from permeable foam eruption one requires a mechanism of stirring to remove the bubbles after vesiculation. Cooling of a magma due to vesiculation reduces temperature and increases viscosity. At temperatures of $850-900^{\circ} \mathrm{C}$ the viscosity of froth or foam is less than vesiculated rhyolite and the froth may be easily extruded reaching the surface faster than the "dry" obsidian. Friedman (1989) has reported that microscopic evidences of such foams have not been found. Contrary to Westrich et al. (1988) we can state that vesiculation of rhyolite will decrease the bulk viscosity at least one order of magnitude.

Presence of relatively low viscosity and deformable froth near the wall of magma conduit changes the hydrodynamical character of flow. According to general view on viscous foam flow in a tube (Kraynik, 1988), near the wall of a magma conduit the velocity of a flow approaches a finite slip value. In the center of conduit there is solid-plug region, between the center and the wall region there is shearing flow of vesicular obsidian. It is interesting to note that some obsidian flows consist of three distinct units (Fink, 1980) finely vesicular pumice evolved from obsidian near the upper flow surface, coarsely vesicular pumice located near the base of the flow, and a layer of glassy bubble-free obsidian. These can be explained by the fact that viscosity of coarsely vesicular pumice is less in ten times that bubble-free obsidian and thus it is extruded first to the surface. In the light of the new viscosity data for rhyolite 


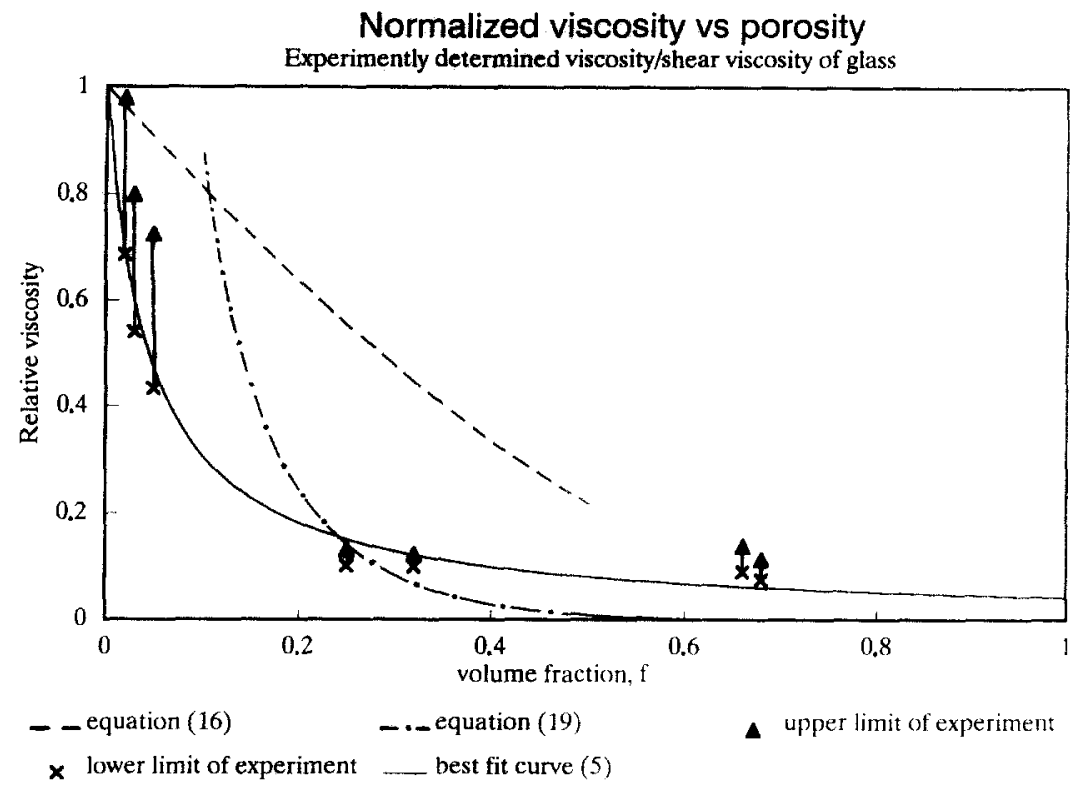

Fig. 7. Viscosity of the spherical void suspension normalized to the shear viscosity of the interstitial liquid.

froth foams the analysis of coarse pumice area spacing on the surface of several flow lobes of Little and Big Glass Mountains (Fink, 1980) requires revision of the viscosity ratio between the obsidian and the coarse pumice layers.

\section{Conclusions}

Results on compressional viscosity measurements of porous and foamed rhyolites prepared from obsidian show a significant difference in their deformation character. The measured viscosity of porous glasses (porosity $<5 \%$ ) decreases with porosity increase. At zero porosity the value tends to $10.94 \pm 0.04 \log _{10}$ (Pa s) which is close to the value of shear viscosity $11.19 \pm 0.1 \log _{10}$ (Pa s) obtained for rhyolite glass without bubbles in elongation experiments (Webb and Dingwell, 1990). In foamed samples (porosity 25-67\%) the compressional viscosity is practically constant at $10.0 \pm 0.1 \log _{10}(\mathrm{~Pa} \mathrm{~s})$. Because of the viscous deformation of bubbles the foamed material behavior is dilatant. At low porosities apparent viscosity measured in parallel plate viscometer refers to the uniaxial shear viscosity.
In porous rhyolite (porosity $<5 \%$ ) the observed behavior is a combination of pure shear flow of glass and viscous deformation of bubbles. At high porosity the volume viscosity of vesicular material plays a significant role in apparent effective viscosity and thus the volume viscosity of foamed materials does not tend to zero when $f \Rightarrow 1$. Detailed studies of natural glasses containing bubbles and pumice materials can reveal the directions of applied stresses under which these materials were erupted. The presence of bubbles in magmatic melts $\left(T \simeq 1200-1600^{\circ} \mathrm{C}\right)$ leads to disturbance of viscous flow and the effective viscosity of magmatic emulsions is expected to increase with increasing volume fraction of bubbles (Stein and Spera, 1992). The present study shows that in highly viscous flows [10$\left.11 \log _{10}(\mathrm{~Pa} \mathrm{~s})\right]$ and at low strain rates ( -5 : $-7 \log _{10} \mathrm{~s}^{-1}$ ) such velocity disturbances can be neglected but the volume viscosity of the medium must be taken into account.

\section{Acknowledgements}

We wish to thank R. Knoche for help with the dilatometer and Sharon Webb for discus- 
sions as well as D. Stein and F. Spera for the manuscript of their article, H. Schulze, D. Krauße, W. Reichstein, G. Gollner (University Bayreuth, FRG) for technical help and sample analysis, B. Coté (Saint-Gobain Recherche, France) for gas-chromatographic analysis of foams and useful references. Authors are grateful to B. Marsh, F. Ryerson, F. Spera and D. Stein for their comments.

\section{Appendix}

Effective volume and shear viscosities of medium with spherical inclusions may be calculated using a self-consistent approach. If $\eta_{\mathrm{v}}$ and $\eta_{\mathrm{s}}$ refer to the effective viscosities of a material, $\tilde{\eta}_{\mathrm{v}}$ and $\tilde{\eta}_{\mathrm{s}}$ to the properties of the interstitial material, and $\eta_{\mathrm{v}}^{0}$ and $\eta_{\mathrm{s}}^{0}$ to the properties of the material in inclusions then, by analogy with elastic moduli, these properties are related by the following equations (Watt et al., 1976):

$\frac{f}{\eta_{\mathrm{v}}-\tilde{\eta}_{\mathrm{v}}}+\frac{1-f}{\eta_{\mathrm{v}}-\eta_{\mathrm{v}}^{0}}=\frac{\alpha}{\eta_{\mathrm{v}}}$

$\frac{f}{\eta_{\mathrm{s}}-\tilde{\eta}_{\mathrm{s}}}+\frac{1-f}{\eta_{\mathrm{s}}-\eta_{\mathrm{s}}^{0}}=\frac{\beta}{\eta_{\mathrm{s}}}$

$\alpha=\eta_{\mathrm{v}} /\left(\eta_{\mathrm{v}}+4 / 3 \eta_{\mathrm{s}}\right)$

$\beta=3-5 \alpha$

In the case of voids $\eta_{\mathrm{s}}^{0}=0$ and $\eta_{\mathrm{v}}^{0}=0$ and the ratio of $\eta_{\mathrm{v}}^{0} / \hat{\eta}_{\mathrm{v}}$ is taken to be small. In the case represented in Figure 6 this ratio is taken to be 0.05 .

\section{References}

Buckmaster, J.D., 1972. Pointed bubbles in slow viscous flow. J. Fluid Mech., 55(3): 385-400.

Cashman, K.V., 1990. Textural constrains on the kinetics of crystallization of igneous rocks. In: J. Nicholls, and J.K. Russel (Editors), Modern Methods of Igneous Petrology. Understanding Magmatic Processes. Rev. Mineral., 24: chapter 10.

Cooper, C.F. and Kitchener, J.A., 1959. The foaming of molten silicates. J. Iron Steel Inst. London, 9: 48-55.

Dingwell, D.B. and Virgo, D., 1988. Viscosities of melts in the $\mathrm{Na}_{2} \mathrm{O}-\mathrm{FeO}-\mathrm{Fe}_{2} \mathrm{O}_{3}-\mathrm{SiO}_{2}$ system and factors controlling the viscosity of fully polymerized melts. Geochim. Cosmochim. Acta, 52: 395-403.

Dingwell, D.B. and Webb, S.L., 1989. Structural relaxation in silicate melts and non-Newtonian melt rheology in geological processes. Phys. Chem. Mineral., 16: 508-516.

Eichelberger, J.C., 1989. Are extrusive rhyolites produced from permeable foam eruptions? Bull. Volcanol., 51: $72-75$.

Fink, J.H., 1980. Gravity instability in the holocene Big and Little Glass Mountain rhyolitic obsidian flows, Northern California. Tectonophysics, 66: 147-166.

Fink, J.H., 1984. Structural geologic constraints on the rheology of rhyolitic obsidian. J. Non-Crystal. Solids, 67: 135-146.

Fontana, E.H., 1970. A versatile Parallel-plate viscosimeter for glass viscosity measurements to $1000^{\circ} \mathrm{C}$. Am. Ceram. Soc. Bull., 49(6): 594-597.

Frankel, N.A. and Acrivos, A., 1970. The constitutive equation for emulsion. J. Fluid Mech., 44(1): 65-78.

Friedman, I., 1989. Are extrusive rhyolites produced from permeable foam eruptions? Bull. Volcanol., 51:69-71.

Gent, A.N., 1960. Theory of the parallel plate viscosimeter. Br. J. Appl. Phys., 11: 85-88.

Hampton, C.M. and Bailey, D.K., 1984. Gas extraction experiments on volcanic glasses. J. Non-Crystalline Solids, 67: 147-168.

Kappel, J., Reinhard, C. and Scholze, H., 1987. Foaming behavior on glass melts. Glastech. Ber., 6: 189-201.

Kraynik, A.M., 1988. Foam flows. Annu. Rev. Fluid Mech., 20: 325-357.

McKenzie, J.K., 1950. Elastic constants of a solid containing spherical holes. Proc. Phys. Soc. London, Ser. B, 63: 2-11.

Murase, T., McBirney, A.R., 1973. Properties of some common igneous rocks and their melts at high temperatures. Geol. Soc. Am. Bull., 84( 11 ): 3536-3592.

Powell, R.L., 1988. Rotational viscosimetry. In: A.A. Collyer and D.W. Clegg (Editors), Rheological measurement. Elsevier Applied Science, London, New York, pp. 247-296.

Ryerson, F.J., Weed, H.C. and Piwinskii, A.J., 1988. Rheology of subliquidus magmas. 1. Picritic compositions. J. Geophys. Res., B93: 3421-3436.

Ripley, B.D., 1981. Spatial Statistics. Wiley, New York, Chichester, Brisbane, Toronto, pp. 208-212.

Sakuyama, M. and Kuhiro, I., 1979. Vesiculation of hydrous andesitic melt and transport alkalies by separated vapor phase. Contrib. Mineral. Petrol., 71: 6166.

Schowalter, W.R., 1978. Mechanics of non-Newtonian fluids. Pergamon Press, Oxford, N.Y., Toronto, Sydney, Paris, Frankfurt, $300 \mathrm{pp}$.

Sheridan, M.F. and Wohletz, K.H., 1981. Hydrovolcanic explosions: the systematics of water-pyroclast equilibration. Science, 212: 1387-1389.

Skorokhod, V.V., 1972. Rheological theory of sintering. Naukova Dumka Publishing House, Kiev, p. 22 (in Russian ).

Sparks, R.S.J., 1978. The dynamics of bubble formation and growth in magmas: a review and analysis. J. Volcanol. Geotherm. Res., 3: 1-37.

Stein, D.J. and Spera, F.J., 1992. Rheology and micro- 
structure of magmatic emulsions: theory and experiments. J. Volcanol. Geotherm. Res., 49: 157-174.

Sura, V.M. and Panda, P.C., 1990. Viscosity of porous glasses. J. Am. Ceram. Soc., 73(9): 2697-2701.

Taylor, G.I., 1932. The viscosity of fluid containing small drops of another fluid. Proc. R. Soc. London, Ser. A, 138: 41-48.

Taylor, G.I., 1954. The two coefficients of viscosity for an incompressible fluid containing air bubbles. Proc. $\mathbf{R}$. Soc. London, Ser. A, 226: 34-39.

Toramaru, A., 1990. Measurement of bubble size distribution in vesiculated rocks with implications for quantitative estimation of eruption process. J. Volcanol. Geotherm. Res., 43: 71-90.

Vergniolle, S. and Jaupart, C., 1986. Separated two-phase flow and basaltic eruptions. J. Geophys. Res., B91: 842-860.

Walsh, J.B., Brace, W.F. and England, A.W., 1965. Effect of porosity on compressibility of glass. J. Am. Ceram.
Soc.. 48(12): 605-608.

Watt, J.P., Davies, G.F. and O'Connel, R.J.O., 1976. The elastic properties of composite materials. Rev. Geophys. Space Phys., 14(4): 541-560.

Webb, S.L. and Dingwell, D.B., 1990. Non-Newtonian rheology of igneous melts at high stresses and strain rates: experimental results for rhyolite, andesite, basalt, and nephelinite. J. Geophys. Res., 95(B10): 15,965-15,701.

Westrich, H.R., Stockman, H.W. and Eichelberger, J.C., 1988. Degassing of rhyolitic magma during ascent and emplacement. J. Geophys. Res., 93 (B6): 6503-6511.

Wilson, L., Sparks, R.S.J. and Walker, G.P.L., 1980. Explosive volcanic eruptions IV. The control of magma properties and conduit geometry on eruption column behavior. Geophys. J. R. Astron. Soc., 63: 117-148.

Wilson, L., Pinkerton, H. and Macdonald, R., 1987. Physical processes in volcanic eruptions. Annu. Rev. Earth Planet. Sci., 15: 73-95. 